\title{
Dynamic Analysis of High Building with Cracks in Column Subjected to Earthquake Loading
}

\author{
Nguyen Thai Chung ${ }^{1}$, Hoang $\mathrm{Hai}^{2}$, Shin Sang Hee ${ }^{3}$ \\ ${ }^{1}$ Department of Solid Mechanics, Le Quy Don Technical University, Ha Noi, Viet Nam \\ ${ }^{2}$ Ministry of Construction, State Authority for Construction Quality Inspection, Ha Noi, Viet Nam \\ ${ }^{3}$ International Cooperation Division, Korea Institute of Civil Engineering and Building Technology, Goyang City, Korea
}

Email address:

thaichung1273@gmail.com (N. T. Chung), hoanghai.inspector@gmail.com (H. Hai)

\section{To cite this article:}

Nguyen Thai Chung, Hoang Hai, Shin Sang Hee. Dynamic Analysis of High Building with Cracks in Column Subjected to Earthquake Loading. American Journal of Civil Engineering. Vol. 4, No. 5, 2016, pp. 233-240. doi: 10.11648/j.ajce.20160405.14

Received: June 25, 2016; Accepted: July 11, 2016; Published: August 2, 2016

\begin{abstract}
This paper is devoted to studying the dynamic response of a high building on an elastic foundation with cracks on the column of the building under earthquake loading using the finite element method (FEM). The authors used a 3D modeling frame - plate system and integration method developed by Newmark, along with construction calculation programs in the Matlab environment to analyze the problem. The results were reflected the effect of the cracks on the columns and other parameters.
\end{abstract}

Keywords: 3D Frame, Plate, Seismic Load

\section{Introduction}

When Ming Ming Yao [1], Mourad Nasser [2], and Sushma Pulikant [3] used the finite element method with a space frame model to simulate a high building under earthquake loading, including foundation replacement via contact connection, they analyzed the dynamic response of the earthquake effect-bearing system. Their findings showed the impacts of foundation parameters as well as structure on the displacement of stories' floors. More recently, Aslan Sadeghi Hokmabadi [4], and Ahmed Abdelraheem Farghaly [5] used the finite element method to calculate the earthquake loading of a high building, including the use of a space frame model for simulating high building and viscous connection foundation modeling elastic spring. This showed the impacts of height on the displacement of stories' floors and shearing force in a high building frame. When D. K. Jain and M. S. Hora [6] used ANSYS software and BEAM4: 3-D elements to describe lateral displacement, SHELL63 to describe the floor surface, and SOLID45 to describe cushion course, they developed the model of a high building under seismic load. J. Sandhya Rani, P. Srinivas Reddy and M. Koti Reddy [7] analyzed high buildings having a water reservoir located in different positions of the overstory under earthquake loading, including situations of different numbers of stories. Their findings showed the effects of the location of the water reservoir on the displacement of the overstory floor and cutting force in the column base. As well, they initially provided some results of cutting force, moment in the footing, and seismic load converted following the equivalent standard. Unlike previous studies, the aim of this article is to study algorithm, calculation method and working conditions and more specifically to select suitable parameters (for structure) for a high building having cracks in the column base. This is an original approach that the authors want to mention in this research.

\section{Finite Element Simulation and Dominant Equations}

A high building is modeled using the frame-plate composite system in the general coordinate system $(\mathrm{X}, \mathrm{Y}, \mathrm{Z})$ under earthquake loading following $\mathrm{X}$ and $\mathrm{Y}$ directions as per Figure 1. 


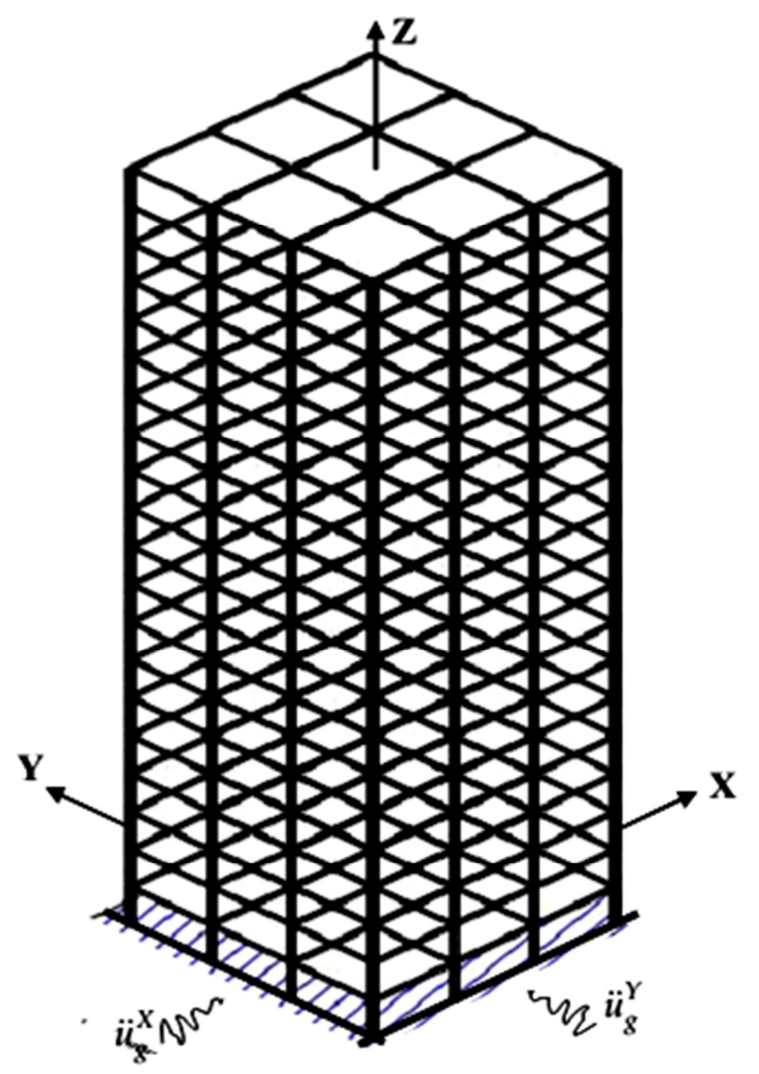

Figure 1. Frame-plate composite system model to simulate high building.

Hypothesis: Materials have a structure of linear elasticity, and small deformation. Panel satisfies Reissner - Mindlin theoretical conditions. Only the horizontal acceleration of the foundation is considered. Construction work columns and foundation operate simultaneously.

\subsection{Response Relation of Elements}

\subsubsection{Space Beam Element Describes the Frame}

The beam element is shown in Fig. 2, and each node has 6 degrees of freedom, including $\mathrm{u}_{\mathrm{i}}, \mathrm{v}_{\mathrm{i}}, \mathrm{w}_{\mathrm{i}}, \theta_{\mathrm{xi}}, \theta_{\mathrm{yi}}, \theta_{\mathrm{zi}}$.

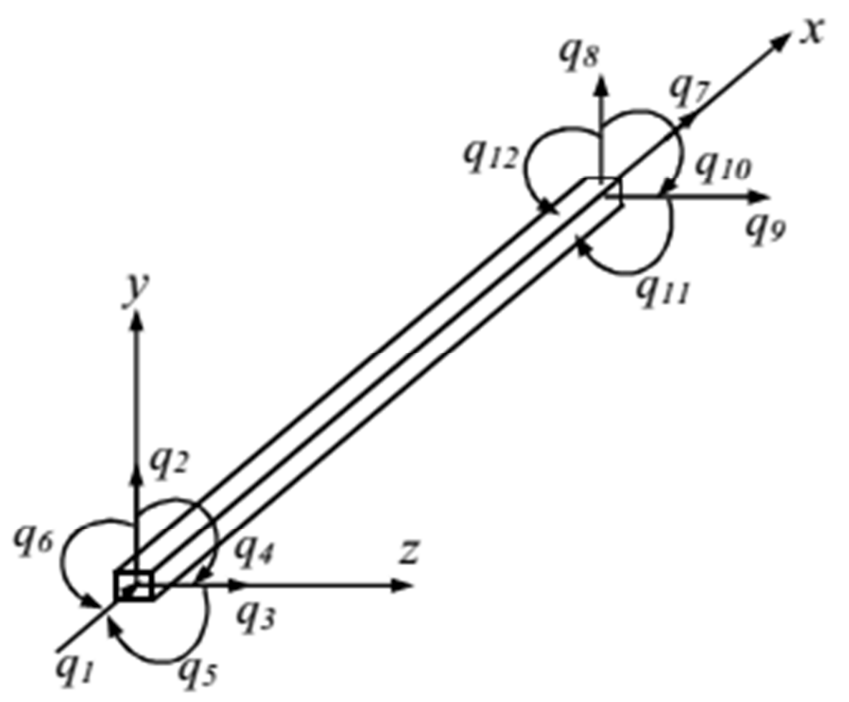

Figure 2. Three dimension 2-node beam element model.
Displacement in any node of the bar with $(\mathrm{x}, \mathrm{y})$ coordinates is identified as follows [8], [10]:

$$
\begin{aligned}
& u=u(x, y, z, t)=u_{0}(x, t)+z \theta_{y}(x, t)-y \theta_{z}(x, t), \\
& v=v(x, y, z, t)=v_{0}(x, t)-z \theta_{x}(x, t), \\
& \mathrm{w}=\mathrm{w}(x, y, z, t)=\mathrm{w}_{0}(x, t)+y \theta_{x}(x, t),
\end{aligned}
$$

where,

the subscript " 0 " represents axis $\mathrm{x}(\mathrm{y}=0, \mathrm{z}=0)$

$\mathrm{t}$ represents time;

$\mathrm{U}, \mathrm{v}$ and $\mathrm{w}$ are the displacements along $\mathrm{x}, \mathrm{y}$ and $\mathrm{z}$;

$\theta_{\mathrm{x}}$ is the rotation of cross section about the longitudinal axis $\mathrm{x}$; and

$\theta_{\mathrm{x}}$ and $\theta_{\mathrm{z}}$ denote rotations of the cross section about $\mathrm{y}$ and $\mathrm{z}$ axes.

The strain components:

$$
\begin{aligned}
& \varepsilon_{x}=\frac{\partial u}{\partial x}=\frac{\partial u_{0}}{\partial x}+z \frac{\partial \theta_{y}}{\partial x}-y \frac{\partial \theta_{z}}{\partial x} \\
& \gamma_{z x}=\frac{\partial u}{\partial z}+\frac{\partial \mathrm{w}}{\partial x}=\frac{\partial \mathrm{w}_{0}}{\partial x}+y \frac{\partial \theta_{x}}{\partial x}+\theta_{y} \\
& \gamma_{x y}=\frac{\partial \mathrm{u}}{\partial y}+\frac{\partial v}{\partial x}=\frac{\partial \mathrm{v}_{0}}{\partial x}-z \frac{\partial \theta_{x}}{\partial x}-\theta_{z}
\end{aligned}
$$

Node displacement vector:

$\{q\}_{e}^{b}=\left\{\begin{array}{llllllllllll}q_{1} & q_{2} & \mathrm{q}_{3} & q_{4} & q_{5} & q_{6} & q_{7} & q_{8} & \mathrm{q}_{9} & q_{10} & q_{11} & q_{12}\end{array}\right\}^{T}$

Element stiffness matrix is set up from 4 types of component stiffness matrices:

$$
\underbrace{[K]_{e}^{b}}_{12 \times 12}=[\underbrace{\left[K_{x}\right]_{e}}_{2 \times 2}+\underbrace{\left[K_{r}\right]_{e}}_{2 \times 2}+\underbrace{\left[K_{x y}\right]_{e}}_{4 \times 4}+\underbrace{\left[K_{x z}\right]_{e}}_{4 \times 4},
$$

where,

$\left[K_{x}\right]_{e},\left[K_{r}\right]_{e},\left[K_{x y}\right]_{e},\left[K_{x z}\right]_{e}$ are tension (compression) stiffness matrix, torsion stiffness matrix, bending stiffness matrix in the xy plane, and bending stiffness matrix in the $x z$ plane, respectively.

In the $(\mathrm{X}, \mathrm{Y}, \mathrm{Z})$ coordinate system, stiffness matrix

$$
\left[K^{\prime}\right]_{e}^{b}=[T]_{e}^{T}[K]_{e}^{b}[T]_{e}
$$

$\underbrace{[T]_{e}}_{12 \times 12}$ is the coordinate axes transition matrix [8].

Similarly, element mass matrix is also established from 4 types of volume matrix:

$$
\underbrace{[M]_{e}^{b}}_{12 \times 12}=[\underbrace{\left[M_{x}\right]_{e}}_{2 \times 2}+\underbrace{\left[M_{r}\right]_{e}}_{2 \times 2}+\underbrace{\left[M_{x y}\right]_{e}}_{4 \times 4}+\underbrace{\left[M_{x z}\right]_{e}}_{4 \times 4},
$$

In the $(\mathrm{X}, \mathrm{Y}, \mathrm{Z})$ coordinate system

$$
\left[M^{\prime}\right]_{e}^{b}=[T]_{e}^{T}[M]_{e}^{b}[T]_{e},
$$


node load vector of element in the natural coordinate system is:

$\underbrace{\{f\}_{e}^{b}}_{12 \times 1}=\left\{\begin{array}{llllllllllll}f_{1} & f_{2} & f_{3} & f_{4} & f_{5} & f_{6} & f_{7} & f_{8} & f_{9} & f_{10} & f_{11} & f_{12}\end{array}\right\}^{T}$

In the $(\mathrm{X}, \mathrm{Y}, \mathrm{Z})$ coordinate system

$$
\{f\}_{e}^{b}=[T]_{e}^{T}\{f\}_{e}^{b}
$$

\subsubsection{Plate Element Describes the Floors}
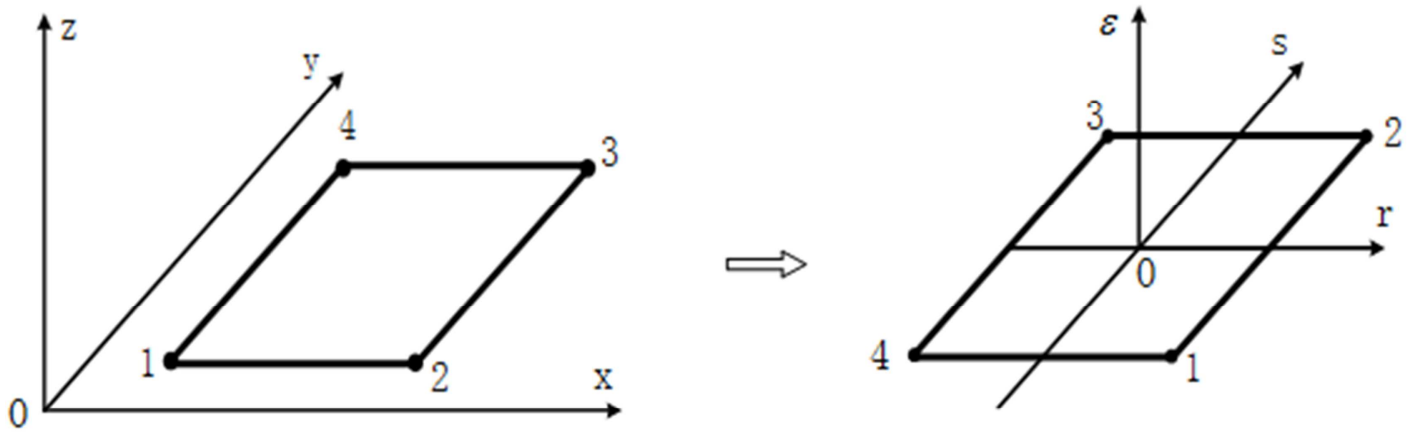

a. In the general coordinate system
The stiffness matrix $[\mathrm{K}]_{e}^{c}$ of the cracked element can be written as:

$$
[\mathrm{K}]_{e}^{c}=[K]_{e}^{b}-[K]_{c}^{b}
$$

where $[K]_{c}^{b}$ is the reduction in the stiffness matrix due to the crack according to Peng et al. [13].

Figure 3. Model of 4-node plate element and the coordinate system.

The displacement fields are written as [8], [12]:

$$
\left\{\begin{array}{l}
u(x, y, z, t)=u_{0}(x, y, t)+z \theta_{y}(x, y, t), \\
v(x, y, z, t)=v_{0}(x, y, t)-z \theta_{x}(x, y, t), \\
w(x, y, z, t)=w_{0}(x, y, t),
\end{array}\right.
$$

where, $\mathrm{u}_{0}, \mathrm{v}_{0}, \mathrm{w}_{0}$ correspond to displacements of plate average, and $\theta_{\mathrm{x}}, \theta_{\mathrm{y}}$ correspond to rotation angle of normal section of the plate plane in the survey node.

Deformation vector:

$$
\left\{\varepsilon_{p}\right\}=\left\{\left\{\begin{array}{lll}
\varepsilon_{x} & \varepsilon_{y} & \left.\gamma_{x y}\right\}
\end{array}\left\{\begin{array}{ll}
\gamma_{x z} & \gamma_{y z}
\end{array}\right\}\right\}^{T}=\left\{\left\{\varepsilon^{b}\right\}^{T} \quad\left\{\varepsilon^{s}\right\}^{T}\right\}^{T}\right.
$$

where,

$$
\begin{aligned}
& \left\{\varepsilon^{b}\right\}=\left\{\frac{\partial u_{0}}{\partial x} \frac{\partial v_{0}}{\partial y}\left(\frac{\partial u_{0}}{\partial y}+\frac{\partial v_{0}}{\partial x}\right)\right\}^{T}+z\left\{\frac{\partial \theta_{y}}{\partial x}-\frac{\partial \theta_{x}}{\partial y}\left(\frac{\partial \theta_{y}}{\partial x}-\frac{\partial \theta_{x}}{\partial y}\right)\right\}^{T}=\left\{\varepsilon_{0}\right\}+z\{\kappa\} \\
& \left\{\mathcal{E}^{s}\right\}=\left\{\begin{array}{ll}
\gamma_{x z} & \gamma_{y z}
\end{array}\right\}^{T}=\left\{\begin{array}{ll}
\frac{\partial \mathrm{w}_{0}}{\partial x}+\theta_{y} & \frac{\partial \mathrm{w}_{0}}{\partial y}-\theta_{x}
\end{array}\right\}^{T} \\
& \{\boldsymbol{\kappa}\}=\left\{\begin{array}{lll}
k_{x} & k_{y} & k_{x y}
\end{array}\right\}^{T}=\left\{\frac{\partial \theta_{y}}{\partial x}-\frac{\partial \theta_{x}}{\partial y}\left(\frac{\partial \theta_{y}}{\partial x}-\frac{\partial \theta_{x}}{\partial y}\right)\right\}^{T}
\end{aligned}
$$

Stress-deformation relation: 


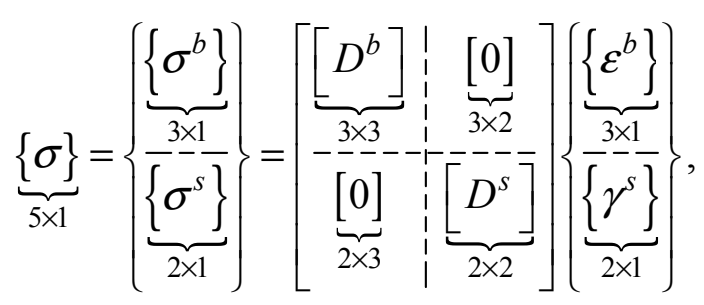

Where,

$\left\{\sigma^{\mathrm{b}}\right\}$ is stress vector excluding shearing force,

$$
\left\{\sigma^{b}\right\}=\left\{\begin{array}{c}
\sigma_{x} \\
\sigma_{y} \\
\tau_{x y}
\end{array}\right\}=\frac{E}{1-v^{2}}\left[\begin{array}{ccc}
1 & v & 0 \\
v & 1 & 0 \\
0 & 0 & \frac{1-v}{2}
\end{array}\right]\left\{\begin{array}{c}
\varepsilon_{x} \\
\varepsilon_{y} \\
\gamma_{x y}
\end{array}\right\}=\left[D^{b}\right]\left\{\varepsilon^{b}\right\}=\left[D^{b}\right]\left(\left\{\varepsilon_{0}\right\}+z\{\kappa\}\right),
$$

$\left\{\sigma^{s}\right\}$ is stress vector caused by horizontal deformation,

$$
\left\{\sigma^{s}\right\}=\left\{\begin{array}{l}
\tau_{x z} \\
\tau_{y z}
\end{array}\right\}=G\left\{\begin{array}{l}
\gamma_{x z} \\
\gamma_{y z}
\end{array}\right\}=\frac{E}{2(1+v)}\left[\begin{array}{ll}
1 & 0 \\
0 & 1
\end{array}\right]\left\{\begin{array}{l}
\gamma_{x z} \\
\gamma_{y z}
\end{array}\right\}=\left[D^{s}\right]\left\{\mathcal{E}^{s}\right\}
$$

E is Young's modulus, and $v$ is the Poisson coefficient of materials.

If using (17) and (18) relations, internal force vector $\left\{\sigma^{\text {if }}\right\}=\left\{\begin{array}{lllll}M_{x} & M_{y} & M_{x y} & Q_{x} & Q_{y}\end{array}\right\}^{T}$ is identified as follows:

$$
\begin{aligned}
& \left\{\begin{array}{lll}
M_{x} & M_{y} & M_{x y}
\end{array}\right\}^{T}=\int_{-\frac{h}{2}}^{\frac{h}{2}} z\left\{\begin{array}{l}
\sigma_{x} \\
\sigma_{y} \\
\tau_{x y}
\end{array}\right\} d z= \\
& {\left[D^{b}\right] \int_{-\frac{h}{2}}^{\frac{h}{2}} z\left(\left\{\varepsilon_{0}\right\}+z\{\kappa\}\right) d z=\frac{h^{3}}{12}\left[D^{b}\right]\{\kappa\},} \\
& \left\{\begin{array}{ll}
Q_{x} & Q_{y}
\end{array}\right\}^{T}=\int_{-h / 2}^{h / 2}\left[D^{s}\right]\left\{\varepsilon^{s}\right\} d z=\alpha h\left[D^{s}\right]\left\{\varepsilon^{s}\right\} .
\end{aligned}
$$

Therefore:

$$
\left\{\sigma^{\mathrm{if}}\right\}=\left[D^{c s}\right]\left\{\varepsilon^{c s}\right\}
$$

where,

$$
\left[D^{c s}\right]=\left[\begin{array}{c:c}
\frac{h^{3}}{12}\left[D^{b}\right] & {[0]} \\
\hdashline[0] & \alpha h\left[D^{s}\right]
\end{array}\right],\left\{\varepsilon^{c s}\right\}=\left\{\begin{array}{lllll}
k_{x} & k_{y} & k_{x y} & \gamma_{x z} & \gamma_{y z}
\end{array}\right\}^{T}
$$

- components of the bending deformation vector and shear deformation vector, and $\alpha=5 / 6$ is the coefficient including shear deformation.

Displacement components of any node of the element [8]:

$$
w=\sum_{i=1}^{4} N_{i} w_{i}, \theta_{x}=\sum_{i=1}^{4} N_{i} \theta_{x i}, \theta_{y}=\sum_{i=1}^{4} N_{i} \theta_{y i},
$$

where,

$\mathrm{w}_{\mathrm{i}}, \theta_{\mathrm{xi}}, \theta_{\mathrm{yi}}$ are displacements of $\mathrm{w}, \theta_{\mathrm{x}}, \theta_{\mathrm{y}}$ at node ith of the element, and written as

$\mathrm{N}_{\mathrm{i}}$ is shape function of node $\mathrm{i}$.

Therefore:

$$
\underbrace{\left\{\varepsilon^{c s}\right\}_{e}}_{5 \times 1}=\underbrace{[B]_{e}}_{5 \times 12} \underbrace{\{q\}_{e}}_{12 \times 1}=\sum_{i=1}^{4}[\underbrace{B_{i}}_{5 \times 3} \underbrace{\left\{q_{i}\right\}}_{3 \times 1} .
$$

where,

$[\mathrm{B}]_{\mathrm{e}}$ is matrix of strain - displacement relation,

$\underbrace{\{q\}_{e}}_{12 \times 1}=\left\{\left\{q_{1}\right\}^{T} \quad\left\{q_{2}\right\}^{T} \quad\left\{q_{3}\right\}^{T} \quad\left\{q_{4}\right\}^{T}\right\}_{e}^{T}$ is element node displacement vector, and

$$
\left\{q_{i}\right\}=\left\{\begin{array}{lll}
w_{i} & \theta_{x i} & \theta_{y i}
\end{array}\right\}^{T} \quad(i=1,2,3,4) .
$$

Replacing (23) with (21) leads to

$$
\underbrace{\left\{\sigma^{\mathrm{if}}\right\}}_{5 \times 1}=\sum_{i=1}^{4} \underbrace{\left[D^{c s} B_{i}\right]}_{5 \times 3} \underbrace{\left\{q_{i}\right\}}_{3 \times 1},
$$

where,

$\left[D^{c s} B_{i}\right]=\left[D^{c s} B_{i}\right]^{b}+\left[D^{c s} B_{i}\right]^{s},\left[D^{c s} B_{i}\right]^{b},\left[D^{c s} B_{i}\right]^{s}$. matrix for calculating bending moment and cutting force.

The total potential energy expression of the element is written as [8]: 


$$
\Pi_{e}=\frac{1}{2} \int_{A_{e}}\left\{\sigma^{\mathrm{if}}\right\}_{e}^{T}\left[D^{c s}\right]\left\{\sigma^{\mathrm{if}}\right\}_{e} d A_{e}-\int_{A_{e}} \mathrm{w} p d A_{e}=\frac{1}{2}\{q\}_{e}^{T}\left[K^{p}\right]_{e}\{q\}_{e}-\{q\}_{e}^{T}\{P\}_{e}
$$

where,

$$
\underbrace{\left[K^{p}\right]_{e}}_{12 \times 12}=\int_{A_{e}}[B]^{T}\left[D^{c s}\right][B] d A_{e}
$$

$\underbrace{\{P\}_{e}}_{12 \times 1}=\int_{A_{e}}[N]^{T} p d A_{e}$ are stiffness matrix and node load vector of the element,

$$
\underbrace{[N]}_{1 \times 12}=\left[\begin{array}{llllllllllll}
N_{1} & 0 & 0 & N_{2} & 0 & 0 & N_{3} & 0 & 0 & N_{4} & 0 & 0
\end{array}\right]
$$

$\mathrm{p}$ is uniform load.

Kinetic energy $T_{e}$ of the element [11]:

$$
T_{e}=\frac{1}{2} \int_{V_{e}} \rho\{\dot{u}\}_{e}^{T}\{\dot{u}\}_{e} d V_{e} \frac{1}{2}\{\dot{q}\}_{e}^{T}\left(\int_{V_{e}} \rho[N]^{T}[N] d V_{e}\right)\{\dot{q}\}_{e}=\frac{1}{2}\{\dot{q}\}_{e}^{T}[M]_{e}\{\dot{q}\}_{e},
$$

where,

$\rho$ is specific volume of material,

$\{\dot{q}\}_{e}$ is node velocity vector,

$\left[M^{p}\right]_{e}$ is element mass matrix, and

$$
\left[M^{p}\right]_{e}=\int_{V_{e}} \rho[N]^{T}[N] d V_{e} .
$$

\subsection{Vibration Equation of the System}

In the event of an earthquake, foundation acceleration causes acceleration $\left\{\ddot{U}_{g}\right\}$ for volume concentrated in nodes of the system, and represented as [7], [9]:

$$
\left\{\ddot{U}_{g}\right\}=\{r\} \ddot{u}_{g},
$$

where,

$\left\{\ddot{U}_{g}\right\}$ is soil acceleration vector,

$\{r\}$ is coefficient vector representing displacement in nodes due to horizontal displacement of soil by unit; vector structure includes elements 1 and 0 upon degrees-of-freedom of each node and number of foundation acceleration dimensions.

$\left\{R_{g}\right\}_{e}$ is loading vector due to earthquake effecting nodes (force of inertial), caused by soil acceleration on node convergence volume of the element.

We have [14]:

$$
\left\{R_{g}\right\}_{e}=-[M]_{e}\left\{\ddot{U}_{g}\right\}=-[M]_{e}\{r\} \ddot{u}_{g} .
$$

Use of Hamilton principle for the element:

$$
\delta \int_{t_{1}}^{t_{2}}\left[T_{e}-\Pi_{e}\right] d t=0
$$

where,

$\mathrm{T}_{\mathrm{e}}$ is kinetic energy and

$\Pi_{e}$ is potential energy of the element.

Then we have the equation of oscillation description of the element:

$$
[M]_{e}\{\ddot{U}\}_{e}+[C]_{e}\{\dot{U}\}_{e}+[K]_{e}\{U\}_{e}=\left\{R_{g}\right\}_{e}+\left\{R_{0}\right\}_{e} .
$$

where $\left\{\mathrm{R}_{0}\right\}_{\mathrm{e}}$ is the external force vector (not earthquake loading).

After combining the matrices and element load vector to become general matrices, and load vector, we have the equation of vibration of the system as follows [14]:

$$
[M]\{\ddot{U}\}+[C]\{\dot{U}\}+[K]\{U\}=\left\{R_{g}\right\}+\left\{R_{0}\right\},
$$

where $\{\ddot{U}\},\{\dot{U}\}$, and $\{U\}$ are the acceleration, velocity, and displacement vectors of the system, respectively;

$[M],[K]$, and $\left\{R_{g}\right\},\left\{R_{0}\right\}$ are the mass, stiffness matrices, earthquake loading vector, and internal force vector, respectively:

$$
\begin{aligned}
& {[M]=\sum_{N b}[M]_{e}^{b}+\sum_{N p}[M]_{e}^{p},[K]=\sum_{N b}[K]_{e}^{b}+\sum_{N p}[K]_{e}^{p}} \\
& \left\{R_{g}\right\}=\sum_{N b}\left\{R_{g}\right\}_{e}+\sum_{N p}\left\{R_{g}\right\}_{e},\left\{R_{0}\right\}=\sum_{N b}\left\{R_{0}\right\}_{e}+\sum_{N p}\left\{R_{0}\right\}_{e}
\end{aligned}
$$




$$
[C]=\alpha_{r}[M]+\beta_{r}[K]
$$

where $\alpha \mathrm{r}, \beta r$ are Rayleigh damping coefficients [7], [11].

After amplitude suppression, (32) becomes:

$$
[\bar{M}]\{\ddot{\bar{U}}\}+[\bar{C}]\{\dot{\bar{U}}\}+[\bar{K}]\{\bar{U}\}=\left\{\bar{R}_{g}\right\}+\left\{\bar{R}_{0}\right\}=\{\bar{R}\} .
$$

This is a linear equation; the correct position of such equation depends on time. This equation is solved using the Newmark direct integral method and programming in the Matlab environment, including the earthquake loading vector updated after each time step.

\section{Finite Element Algorithm}

Step 1. Assign initial conditions

Step 2. Calculate initial parameters, give foundation acceleration chart function $\left(\Delta t_{i}-\ddot{u}_{g}^{X}\right),\left(\Delta t_{i}-\ddot{u}_{g}^{Y}\right)$;

Step 3. Conduct integral cycle in each time step:

- Update node load vector caused by earthquake;

- Identify vectors of displacement, velocity, acceleration and internal force;

Step 4. Export results.

The calculation program was developed by the authors, and is called 3D_frame_earthquake.m.

\section{Numerical Results and Discussion}

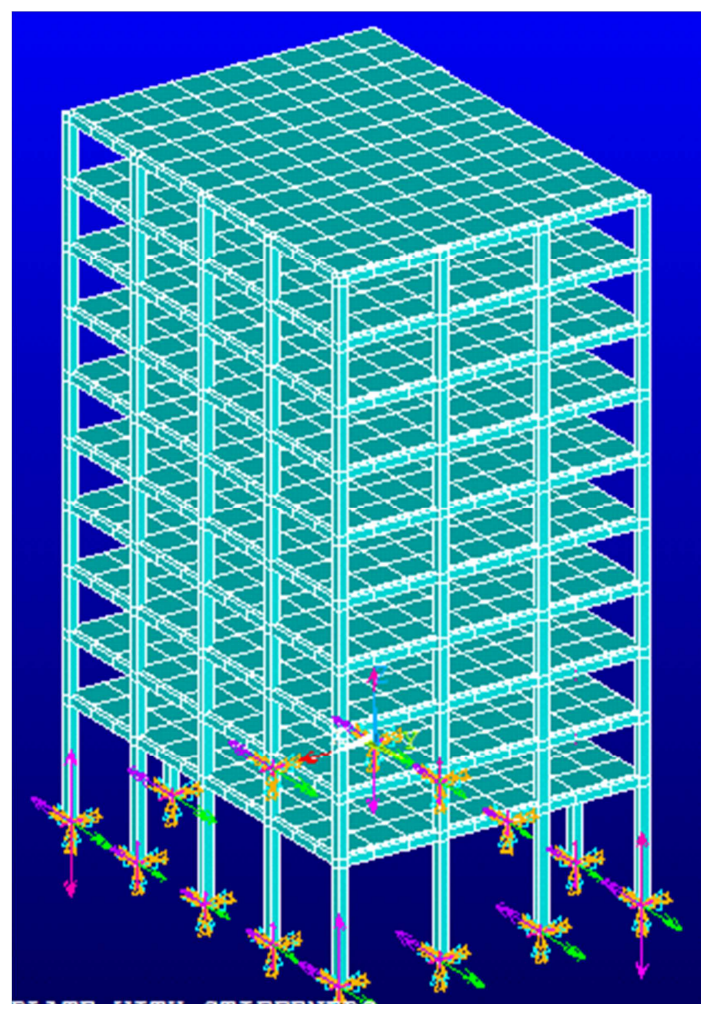

Figure 4. Finite element modeling.

The 9-story building is calculated with the model of a frame-plate system, including 20 vertical columns, 90 beams and 10 floors. They are described to be flat slabs, the general story has a height of $\mathrm{h}_{0}=5 \mathrm{~m}$. For the 9 remaining stories, each story has a height of $h_{i}=3.5 \mathrm{~m}$, total height level of the building $\mathrm{H}=6 \mathrm{~m}+9 \mathrm{~h}_{\mathrm{i}}=36.5 \mathrm{~m}$, width $\mathrm{W}=4 \times 6 \mathrm{~m}=24 \mathrm{~m}$, depth $\mathrm{B}=3 \times 6 \mathrm{~m}=18 \mathrm{~m}$. Cross section of columns is $0.55 \mathrm{~m} \times 0.55 \mathrm{~m}$, beams are $0.3 \mathrm{~m} \times 0.5 \mathrm{~m}$, and floors' thickness is $0.15 \mathrm{~m}$. Columns and floors are made of reinforced concrete with properties of $\mathrm{E}=3.64 \times 10^{10} \mathrm{~N} / \mathrm{m}^{2}, v=0.3, \rho=$ $2.76 \times 10^{3} \mathrm{~kg} / \mathrm{m}^{3}$. The middle column base of the building has a V- shaped crack with a depth of $\mathrm{h}_{0}=0.1 \mathrm{~m}$. Finite element model of the building is shown in Fig. 4. The soil acceleration influencing 2 directions, including $\ddot{u}_{g}^{X}$, $\ddot{u}_{g}^{Y}=0,25 \ddot{u}_{g}^{X}$ is shown in Fig. 5 .

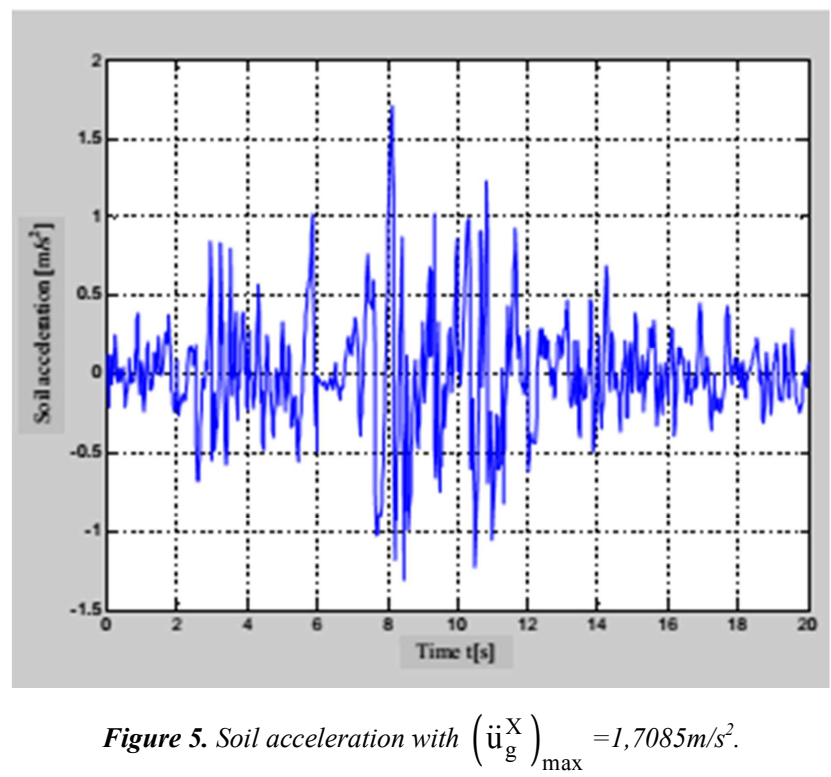

Results export: Central point of the $9^{\text {th }}$ story's floor (point A) and column base in the middle and front sides of the building (point B).

The displacement $\mathrm{u}$ at the point $\mathrm{A}$ and bending moment $\mathrm{M}_{\mathrm{y}}$ at the point B are shown in Fig. 6, 7 following time.

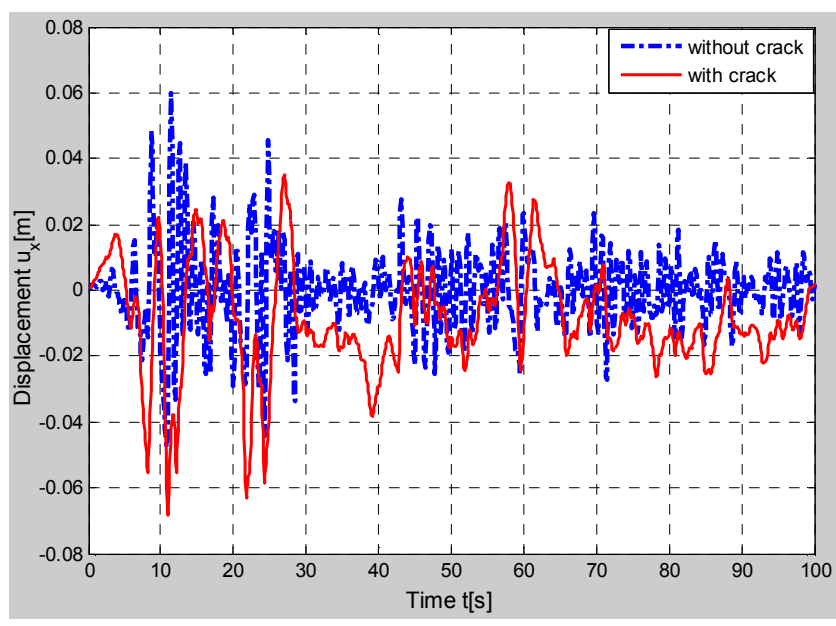

Figure 6. Time history of $u$ displacement. 


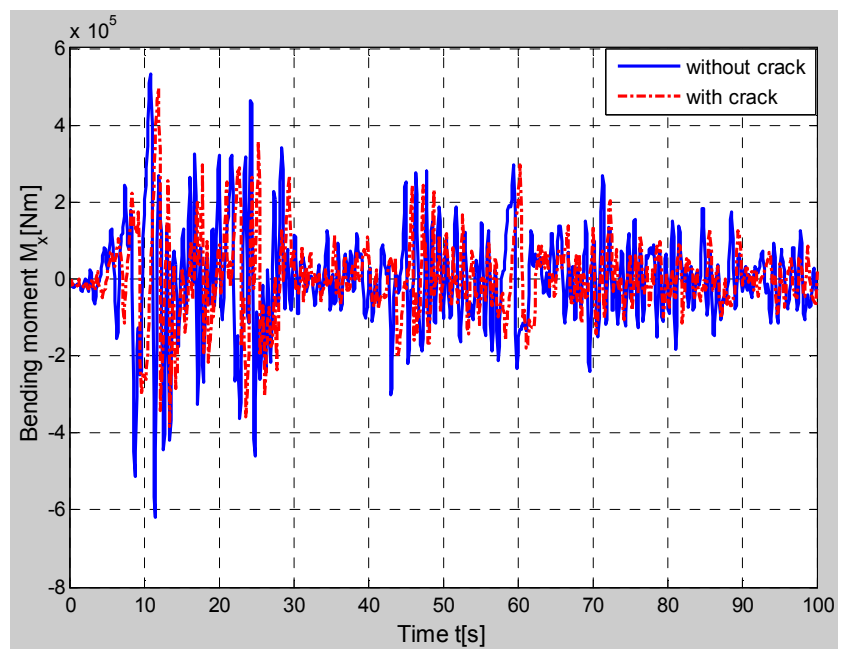

Figure 7. Time history of bending moment.

The maximum displacement $\left(\mathrm{u}_{\max }\right)$ and bending moment $\left(\mathrm{M}_{y}^{\max }\right)$ are shown in Table 1.

Table 1. The maximum of the displacement and bending moment (with crack and without crack).

\begin{tabular}{llll}
\hline $\mathbf{u}_{\mathbf{m a x}}[\mathbf{m}]$ & & $\mathrm{M}_{\boldsymbol{y}}^{\max }[\mathbf{N m}]$ & \\
\hline with crack & without crack & with crack & without crack \\
0.0684 & 0.0598 & $4.9535 \mathrm{e}+05$ & $6.1870 \mathrm{e}+05$ \\
Error: $14.38 \%$ & & Error: $19.94 \%$ & \\
\hline
\end{tabular}

The crack affects the dynamics of the building accordingly in the event of an increase in the cracks in the column, and the displacement of the building.

\subsection{Influences of Damping}

Survey is conducted in two scenarios, with damping and without damping. The results in terms of horizontal displacement and bending moment at points $\mathrm{A}$ and $\mathrm{B}$ are as shown in Figs. 8, 9 and Table 2.

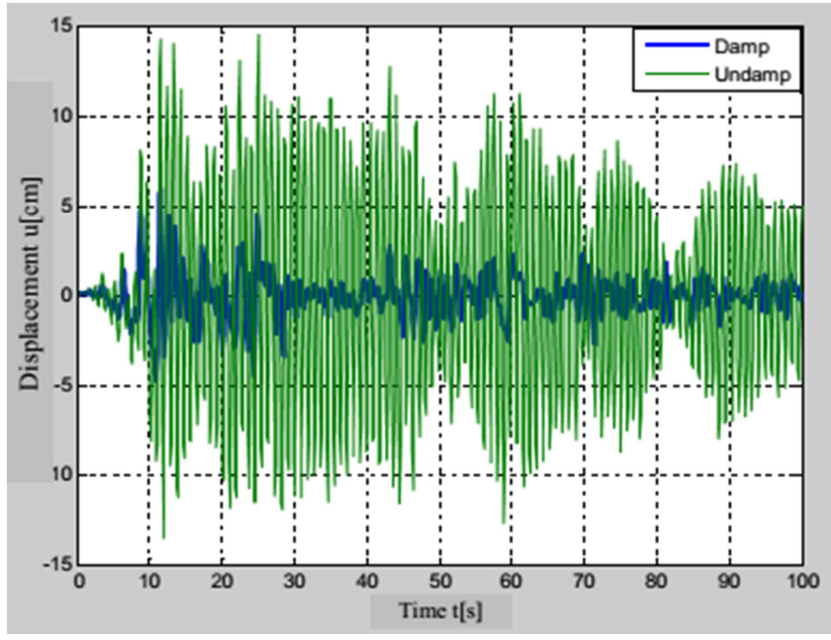

Figure 8. Time history of u displacement.

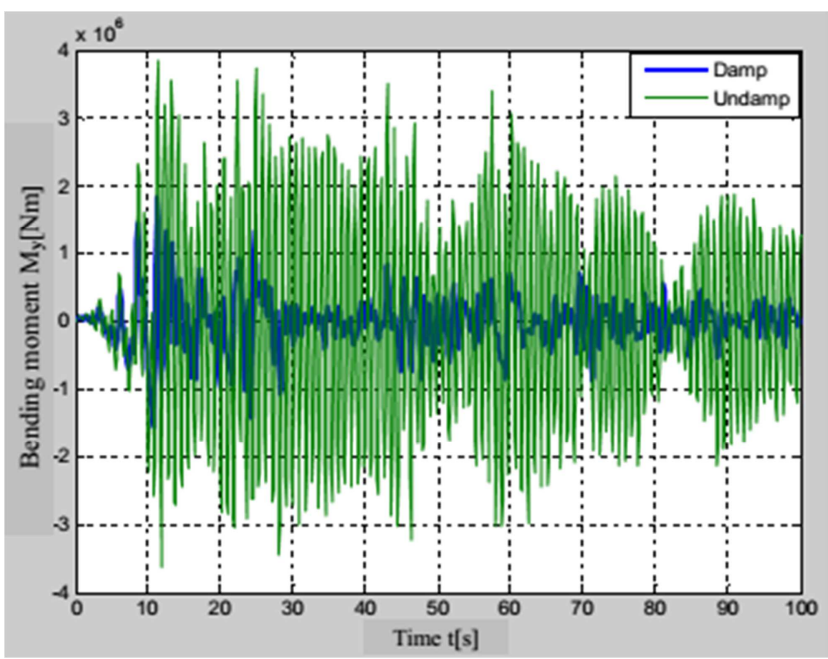

Figure 9. Time history of bending moment.

Table 2. The maximum of displacement and bending moment (with damping and without damping).

\begin{tabular}{llll}
\hline $\mathbf{u}_{\max }[\mathbf{m}]$ & $\mathrm{M}_{\boldsymbol{y}}^{\max }[\mathbf{N m}]$ & \\
\hline with damping & without damping & with damping & without damping \\
0.0684 & 0.1432 & $4.9535 \mathrm{e}+05$ & $7.1462 \mathrm{e}+05$ \\
Error: 2.09 times & Error: 44.27\% & \\
\hline
\end{tabular}

The damping of the structures affects the dynamic of the building and reduces the displacement and internal force.

\subsection{Influences of the Building Height}

The relationship between the height of the building end the displacement of the floors of each story is shown in Fig. 10.

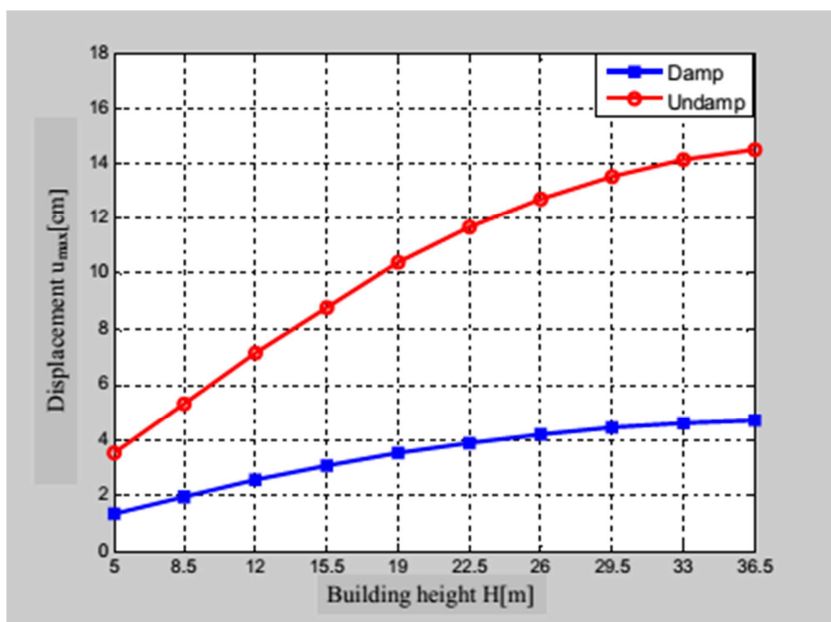

Figure 10. Relationship between the height of the building and the displacement of floors.

Comment: Displacement of the building has a non-linear dependence on the height of the building; it increases quickly when $\mathrm{H} \in[5 \div 22.5] \mathrm{m}$ (2.98 times-with damping, 3.36 times-without damping) and slowly when $\mathrm{H} \in[22.5 \div 36.5]$ $\mathrm{m}$ (1.28 times-with damping, 1.26 times-without damping). This shows that the solution of decreasing vibration in intermediary positions of the building is reasonable. 


\section{Discussion of Results}

Our research arrived at several main results, including the development of an algorithm and dynamic analysis program for high buildings under earthquake loading, foundation acceleration following two orthogonal directions in the horizontal plane, and the use of a 3D modeling frame-plate system with cracks on the main column. The numerical analysis conducted in some Mathematics problems with changing parameters reflects the suitability of the calculation model; algorithm and calculation capacity of the program. The results contribute to the calculation, design and selection of reasonable solutions for new design, diagnosis of damages and reinforcement of modern high buildings.

\section{References}

[1] Ming Ming Yao, (2010), Earthquake Wave-Soil-Structure Interaction Analysis of Tall Building, Doctoral Thesis, University of Victoria.

[2] Mourad Nasser, (2012), Quality Assessment of Dynamic SoilStructure Interaction Models Using Energy Measures, Doctoral Thesis, Bauhaus-University at Weimar Faculty of Civil Engineering.

[3] Sushma Pulikanti (2013), Affect of soil-foundation-structure interaction on seismic behaviour of pile supported frame building, Doctoral Thesis, International Institute of Information Technology - Hyderabad.

[4] Aslan Sadeghi Hokmabadi, (2014), Effect of Dynamic SoilPile-Structure Interaction on Seismic Response of Mid-Rise Moment Resisting Frames, Doctoral Thesis, Faculty of Engineering and Information Technology University of Technology Sydney (UTS).

[5] Ahmed Abdelrahem Farghaly and Ali Mohamed Abdallah (2014), Evaluation of Seismic Retrofitting Techniques Used in Old Reinforced Concrete Building, IOSR Journal of
Engineering (IOSRJEN), ISSN (e): 2250-3021, ISSN (p): 2278-8719, Vol. 04, Issue 06 (June. 2014), pp. 14-22.

[6] D. K. Jain and M. S. Hora, (2014), Interaction analysis of space frame-shear wall-soil system to investigate foundation forces under seismic loading, Department of Aerospace Engineering, Korea Advanced Institute of Science and Technology.

[7] J. Sandhya Rani, P. Srinivas Reddy, M. Koti Reddy (2015), Time history analysis of building structures with water tank as passive tuned mass damper, International Journal of Research in Engineering and Technology eISSN: 2319-1163, Pissn: 2321-7308, pp. 84-90.

[8] Anil K. Chopra (2004), Dynamics of structures theory and applications to earthquake engineering (Second edition), Pearson education Asia limited and Tsinghua university press.

[9] Bathe K. J and Wilson E. L (1978), Numerical Method in Finite Method Analyis Prentice, Hall of India Private Limited, New Delhi.

[10] David J. Dowrick (1988), Earthquake resistant design for engineers and architects, Singapore, Chichester, New York, Brisbane, Toronto.

[11] Stanislav Stoykov (2012), Nonlinear vibrations of 3D beams, Doctor of Philosophy, University of Porto.

[12] Wolf J. P (1988), Dynamic Soil-Structure Interaction Analysis in Time domain, Prentice-Hall Inc. Englewood Cliffs, N. J. 07632.

[13] Reddy J. N (2004), Mechanics of Laminated Composite Plates and Shells: Theory and Analysis, CRC Press.

[14] Peng, Z. K., Lang, Z. Q., Billings, S. A. (2007), Crack detection using nonlinear output frequency response functions, Journal of Sound and Vibration, 301. Pp. 777-788.

[15] Nguyen Thai Chung, Hoang Hai and Nguyen Quang Minh (2015), Dynamic analysis of tall building in the $3 D$ frameplate under seismic load, Journal of Construction, Vietnam, pp. 65-69. 